\title{
What Difference can a Basketball Make?
}

\begin{abstract}
"Sport can play a role in improving the lives of individuals, not only individuals, I might add, but whole communities." ${ }^{\text {, }}$ said the former Secretary General for the United Nations, Kofi Annan. A Danish organization, GAM3, has been testing this statement over the past three years, in their efforts in Lebanon and Egypt. GAM3 uses street basketball and urban culture as tools for empowerment and encouraging tolerance and cross cultural dialogue between youth from different religious, cultural and social backgrounds. The question remains whether it is possible to transpose a Danish project to the Middle Eastern setting and what difference a basketball can make in this connection? This essay will not give definitive answers but will cast light on the field of sports and self-development, through first hand experiences of a Country Director at GAM3-Lebanon and the Managing Director at the GAM3 Headquarters office in Denmark.
\end{abstract}

\section{CREATING DENSER INTERSUBJECTIVITY IN DEN- MARK}

GAM3 started as a Danish non-profit organization in 2002 and, despite its now refined program-
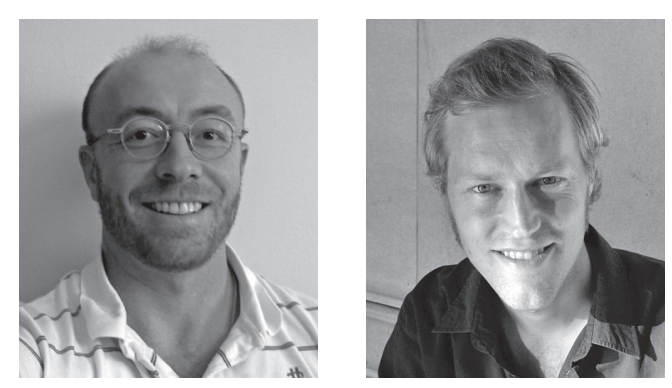

BY

MAC

MCCLENAHAN AND SIMON

PRAHM me, its methodology has remained a fusion of street basketball, urban dance and hip hop music as tools to reach out to youth.

By using basketball and hip hop, GAM3 now has a proven track record in Denmark of empowering youngsters (mainly of non-Danish ethnicity) in their own neighborhoods using these currently mainstream cultural activities. A thesis by Julie Cold and Katrine Stenild, from the University of Copenhagen's Department of Sociology, used Axel Honneth's 'theory of recognition' to investigate how self-confidence can be 
raised among GAM3 participants. It concludes that many of the youth are at great risk of becoming involved with criminal activities because of the socially challenging environment in which they live. It also reveals how GAM3 offers the young individuals a humiliation free social stage that promotes their feelings of pride instead of marginalization. GAM3 is proving to be an essential building block on the road to denser inter-subjectivity among the teenagers. ${ }^{2}$

But does a proven Danish track record automatically make GAM3's methods relevant for dealing with the development and reform challenges facing youth in the Middle East? Challenges in the region are well known and, over the last decades, various humanitarian organizations have targeted the Middle East with a wide variety of projects. Oddly enough, sports seem not to be among their approaches. As the challenges remain unresolved in the region, relations with the Western world have also seen setbacks. So why not use sports as a strategic approach to empower the youth to move beyond some of the central challenges in the region.

\section{MIDDLE EAST STREET BASKETBALL PROJECT (MESBP)}

In 2006, GAM3 identified Egypt and Lebanon as pilot-project countries for what is today known as the Middle East Street Basketball Project (MESBP). Just prior to the project's launch, the Mohammad cartoon controversy stormed in, and protests from the Muslim world over the Jyllands-Posten drawings developed into what turned out to be the worst foreign political crisis for Denmark since World War II. GAM3 decided to postpone the MESB project for a year.

Today, the project is in its third season and has seen continual improvement in both participation and goal achievements, allowing GAM3 to make a positive impact in Lebanon. This success was achieved through two parallel tracks necessitated by the dual challenges of running an NGO in a deeply divided Lebanese society and wildly turbulent political reality. First, GAM3 methods were adapted to regional and historical circumstances in order to maintain a consistent flow of activity. Second, GAM3-Lebanon constantly reinforced a clear and consistent message of GAM3's vision and strategy of using street basketball as a means to unite and empower the youth of Beirut's splintered neighborhoods as well as to raise the organization above any corruption with which other locally based organizations, clubs, and some aimless NGOs were labeled.

Securing the right people for the job was essential. GAM3 staff and coaches, who often took a pay-cut to work for the organization, have high expectations of themselves. However, the turbulence of daily life in Lebanon forced some turnover amongst the staff, leaving a loyal and dedicated core team to deliver the GAM3 agenda. This turnover did result in expanding the group of coaches to include staff from all political and religious backgrounds, who accomplished amazing results relative to Lebanese and global norms. Some examples include continuing practices during the armed clashes in April 2007 and May 2008; organizing the largest street-basketball tournaments in Lebanon (and the region) in 2008 and 2009 during a time of political crisis, protests and clashes between communities. In this troubled environment GAM3 activities were not only implemented but participation has expanded today from a single neighborhood 'GAM3 Zone' in 2007 to seven 'GAM3 Zones'.

The breadth of GAM3's impact in Lebanon can be measured by the number of youth who 


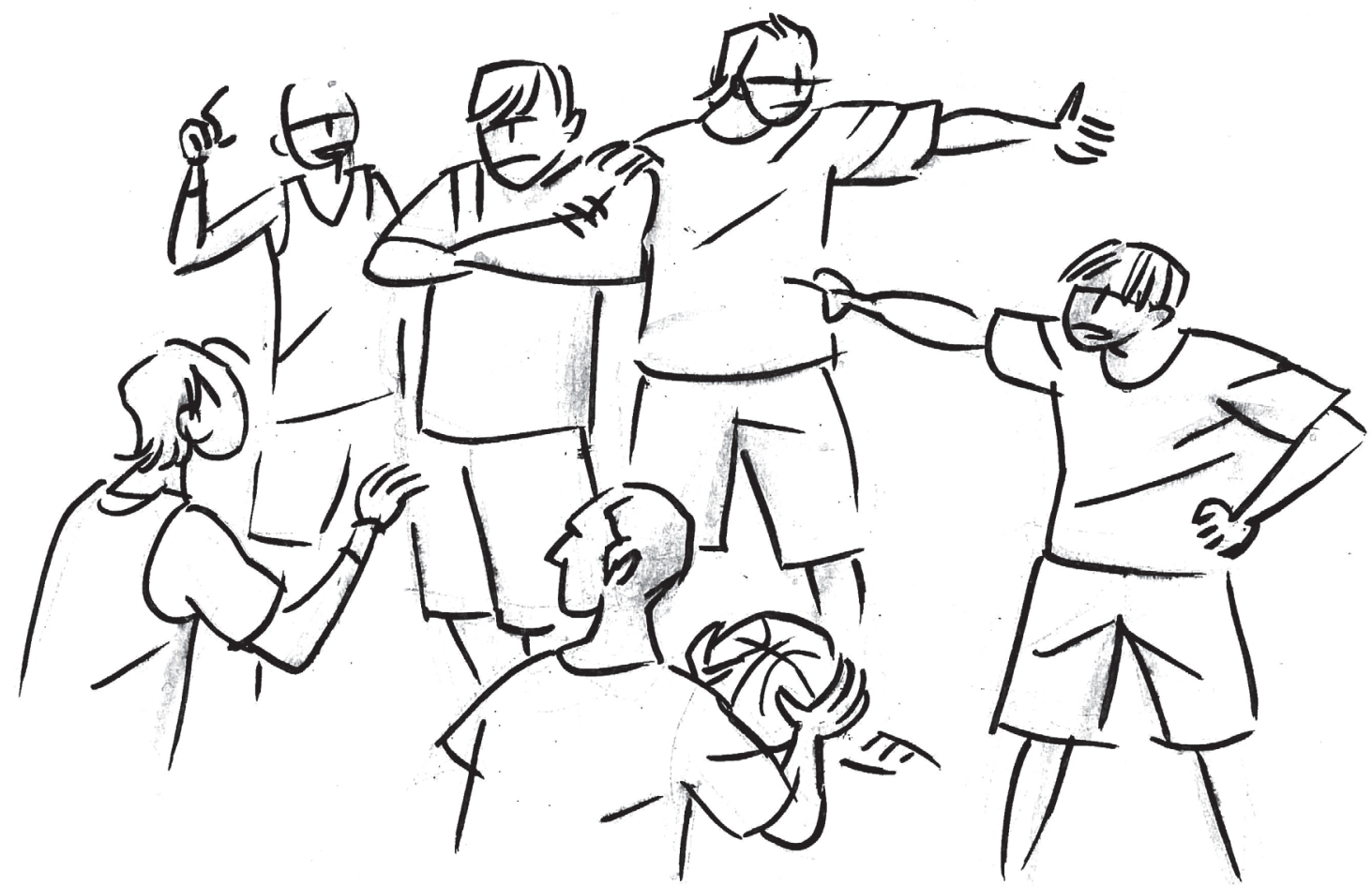

Building democracy. Through the drills in the GAM3 Compendium, the participants work with a series of training themes. In the shown drill they experience the difference between democracy and dictatorship (Illustration by Palle Schmidt).

participate in GAM3 activities, as well as by the geographic spread in which GAM3 is present and accessible. The number of participants has grown consistently and spans the entire cultural and political spectrum, i.e. from the Armenian Christian neighborhood of Bourj Hammoud to the Shiite Muslim enclave of Bourj al-Barajneh (the target of the heaviest bombardment in the 2006 war with Israel) in 2009. The GAM3 coaching staff has increased from 5 to 26 coaches, some of whom are currently completing their third year as GAM3 Coaches and Managers.

\section{BREAKING OUT OF THE COMFORT ZONE}

The depth of GAM3's impact, while much harder to measure than its participation rate and geographic presence in Beirut, has nonetheless begun to produce noticeable results among the youth, community spaces and community organizations in contact with GAM3.

Youth from every community and from every background in Beirut, have shown dedication, loyalty, the ability to team-build, and a willingness to break out of the comfort zone of their home basketball court to excel and interact with 
others on an equal footing provided by GAM3 zones and tournaments. For the youth in the Greater Beirut area, "sports-for-all” is a foreign concept. In their view, sports exist for the privileged few with money, political connections or who are lucky enough to live close to one of the three public playing areas that service Beirut's 1.5 million population.

Public spaces have been changed by GAM3 in sustainable ways. Through basketball court renovations and thousands of attendances at weekly practices, the courts that were once dormant or unusable are now teeming with youth; both GAM3 members and locals who sneak onto the courts outside of practice hours. Currently these courts host an average of 50 youth daily who did not previously have a place to play. Not least, GAM3 has impacted those organizations with which it works, i.e. over 25 schools and organizations dedicated to helping youth. These organizations have begun organizing more sports activities, including a full blown streetbasketball tournament based on the GAM3 model, rules and coaching techniques, and have even borrowed or hired GAM3 coaches for some of their own activities.

Providing an open or free opportunity to play basketball often provokes turf battles and encourages communitarian behavior. One of the lessons learned from the experience of GAM3 in Lebanon is that it takes time, repeated effort and consistency to build trust and become a role-model for youth. And only after winning this trusted position with both the players and staff can a difference be made.

\section{\$10.000 FOR A ONE-YEAR MEMBERSHIP}

In Cairo, Egypt, the participants comprise either orphans or street children and who are unfamiliar with participating in organized sports with professional coaches. In many Middle Eastern countries sports appear to be reserved for the elite and in Cairo this principal is taken to the extreme. Annual membership in one of the established sport clubs in Cairo costs approximately \$10.000, automatically excluding the poorer strata of Egyptian society. While time spent on studying, work/chores, religion, and family is seen as honorable, semi-organized physical leisure activities is not. GAM3's mission is to change this perception by providing professional coaches for the street children to show them the value of achievement on a basketball court. With a very simple tool - basketball - the project focuses on reducing political, religious, and social distances between groups by creating physical interaction and dialogue between participants on the court.

Girl power. A special focus of the MESBP has been help the girls claim their rights to equal participation in the public sphere (Illustration by Palle Schmidt).

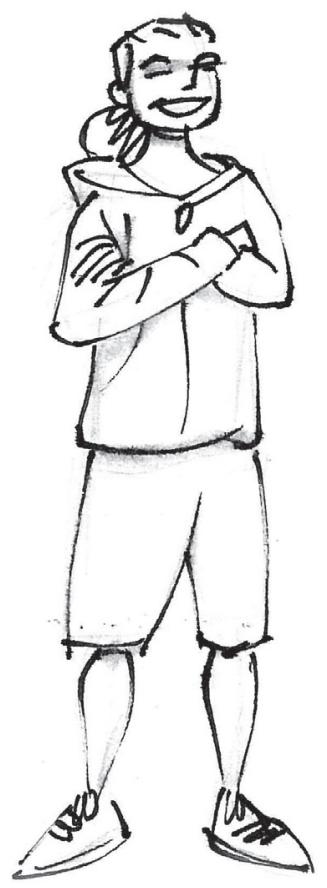


Sports can be taught in many ways and didactics can vary from one extreme to another even within the same sports discipline. The democratic approach, highly valued among coaches in Scandinavia allows players to voice their opinions during practice sessions. This approach cannot be taken for granted in the Middle East. One example is an incident that GAM3 encountered during its first season in Egypt when a coach brought a stick to practice which he planned to use to keep the children in line. GAM3 immediately reacted by becoming more explicit about its intended methodology for coaching and invested in capacity building for the local staff in both Egypt and Lebanon.

\section{AN EMPOWERING BASKETBALL COMPENDIUM}

As GAM3 efforts in the Middle East advanced, the capacity building process resulted in the development of a new Basketball Compendium in English and Arabic which, in combination with a coaching seminar, introduced the coaches to GAM3 didactics and methodology. The compendium introduces three levels of empowerment (individual, social, and community) that can be delivered through a series of 13 corresponding Training Themes (leadership, trust, democracy etc.).

The new compendium has proven to be a viable tool for capacity building of local coaches in Denmark, Egypt and Lebanon. Using an "open source" approach, the coaches have become cocreators of the compendium, contributing drills and feedback during the 12 months leading up to printing of the second edition. This has strengthened the usability of the compendium and simultaneously has given the coaches ownership of the methodology and consequently increased the sustainability of the project.

By creating a space where youth can meet and come together with a common focus - sports-, GAM3 project participants get a chance to recognize their own potential both in sports as well as in other aspects of their lives. Sport has proven to be a great tool for achieving this within the immigrant community in Denmark as well as in the Middle East where many youth live in poverty and conflict.

While challenges will continue, sports can provide hope to overcome them, through its unpretentious and equal footing approach, leaving the beneficiaries as stronger individuals with the social skills necessary to make a positive difference in their communities.

\section{NOTES}

1. http://www.partners.net/partners/Sport_for_Development_EN.asp?SnID=2

2. J. C. Cold \& K. S. Petersen (2006). Anerkendelse gennem streetbasket - om anerkendelse af etniske minoritetsunge $i$ socialt udsatte boligområder gennem streetbasketprojektet GAM3. Master thesis. Dept. of Sociology, University of Copenhagen.

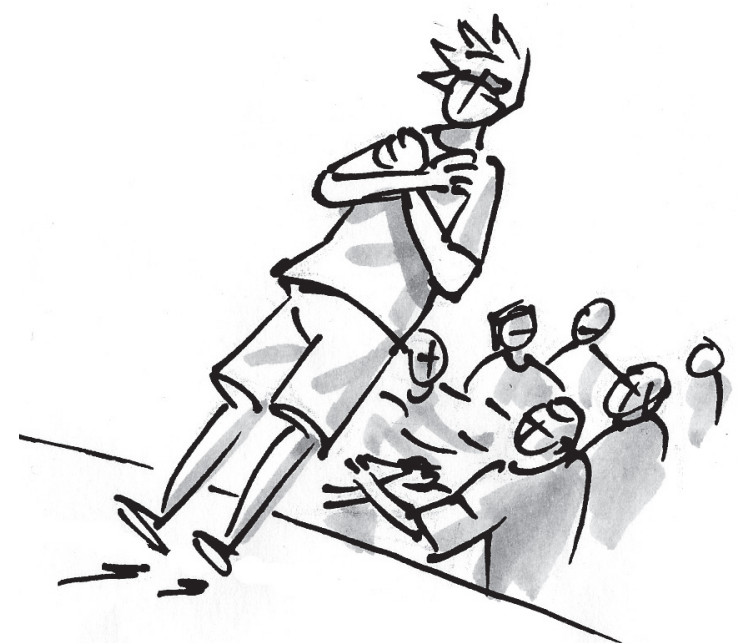

Trust your teammates. By using simple drills trust is being built among diverse political, religious, and ethnic groups (IIlustration by Palle Schmidt). 